\title{
Schmitt Trigger with Controllable Hysteresis Using Current Conveyors
}

\author{
Jiri Misurec and Jaroslav Koton
}

\begin{abstract}
Active elements working in the current or mixed mode are still attractive for the design of analog functional blocks. The current conveyor (CC) was defined already in 1968. This paper deals with hysteresis comparators using second generation current conveyor. The comparator is basically a pulse circuit. In these circuits, the maximum rate of change in the output voltage is required during switching from one state to another. In comparators with operational amplifiers the switching time is given by the slew rate of the operational amplifier used, which is not too high. If a current conveyor is used, the time of switching the comparator gets shorter. The comparator is capable to operate at a higher frequency bands and if it is used, for example, in converters, a higher operating frequency can be reached. The connection of an inverting and a non-inverting comparator with adjustable hysteresis is shown as a practical implementation. Using the AD844, results of experimental measurements are presented that confirm the theoretical assumptions and the results of computer simulation.
\end{abstract}

Keywords-Current conveyor, analog circuit design, hysteresis comparator

\section{INTRODUCTION}

The current conveyors as active elements are known since 1968 [1], when Smith and Sedra presented the first-generation current conveyor (CCI). Later on the the second- and thirdgeneration current conveyors have been designed [2], [3]. These elements are now with advantage used in applications, where the wide bandwidth or current output response is necessary. Nowadays, different types of current conveyors are described that are mostly based on the CCII, e.g. current controlled CC (CCCII) [17], differential voltage CC (DVCC) [18], or electronically tunable CC (ECCII) [19], [20].

The application possibilities of current conveyors are mostly presented on linear circuit design, e.g. frequency filters [4]-[7] or immittace simulators $[8]-[11]$. However, the CCII can be used to implement other functional blocks, such as Schmitt trigger circuit, by creating a regenerative feedback that takes part of the output voltage from terminal $\mathrm{Z}$ and applies it to the $Y$ terminal of the active element [12], [13]. Schmitt Triggers based on other active elements such as Current Through Transconductance Amplifier (CTTA) or Current Differencing Transconductance Amplifier (CDTA) can be found e.g. in [14], [15].

In this paper we use simple second-generation current conveyors to implement Schmitt trigger with inverting and non-inverting hysteresis loop. First basic circuit topology is described that is subsequently supplemented by and digital-to

J. Misurec and J. Koton are with the Department of Telecommunications, Brno University of Technology, Purkynova 118, 61200 Brno, Czech Republic. Corresponding author: misurec@feec.vutbr.cz.

Manuscript received July 5, 2012; revised September 29, 2012 analog converter with reference input enabling digital control the value of hysteresis of the Schmitt trigger. The behavior of the proposed circuit is analyzed both by SPICE simulations and experimental measurements showing the performance of the Schmitt trigger.

\section{SECOND-GENERATION CURRENT CONVEyor AND ITS IMPLEMENTATION}

Generally, in the second-generation of current conveyors, terminal $\mathrm{Y}$ is only a voltage terminal having infinite input impedance in theory. The $X$ port is the current input and the current transfer from port $\mathrm{X}$ to port $\mathrm{Y}$ is zero, from $\mathrm{X}$ to $\mathrm{Z}$ it is unity. A three-port is involved here (see Fig. 1), the matrix representation of which is given by relations:

$$
\left[\begin{array}{c}
V_{\mathrm{X}} \\
I_{\mathrm{Y}} \\
I_{\mathrm{Z}}
\end{array}\right]=\left[\begin{array}{lll}
0 & 1 & 0 \\
0 & 0 & 0 \\
1 & 0 & 0
\end{array}\right]\left[\begin{array}{c}
I_{\mathrm{X}} \\
V_{\mathrm{Y}} \\
V_{\mathrm{Z}}
\end{array}\right] .
$$

Its advantageous properties and application possibilities have grown with the development of circuits and systems in the current mode. Second-generation current conveyors have come to feature prominently in circuit structures of some commercially manufactured circuits. The AD844 circuit is a transimpedance amplifier (Analog Devices). In its internal structure there is a CCII+ second-generation current conveyor. A high-impedance outlet is important here, which is used as port $\mathrm{z}$ of the CCII+ conveyor. The internal connection of the circuit is shown in Fig. 2(a), the schematic symbol of the AD844 circuit in the PSpice program is in Fig. 2(b) and the ideal model is in Fig. 2(c).

It is evident from the equivalent circuit connection that its internal connection consists of two voltage followers and one current follower. Current $I_{\mathrm{IN}}$ flows via input resistance $\mathrm{R}_{\mathrm{IN}}$ (the input resistance of low-impedance terminal is ca. $50 \Omega$ ). This current is detected by the current follower and transferred to the transimpedance terminal.

The current passage through the so-called transimpedance produces a voltage, which is conveyed to the compensation terminal. On this terminal the output current $I_{Z}$ of the current conveyor is obtained too. For the sake of load separation

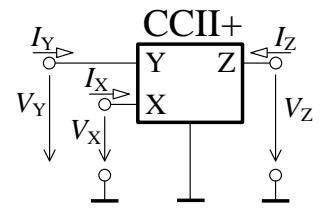

Fig. 1. Schematic symbol of CCII+ second-generation current conveyor 
a voltage follower is included on the voltage output of transimpedance amplifier. However, in the case of current conveyor the voltage output is not made use of. The transimpedance models the impedance of output terminal $\mathrm{Z}$ and is formed by a parallel combination of resistance $\mathrm{R}_{\mathrm{t}}$ (its magnitude is ca. $3 \mathrm{M} \Omega$ ) and capacitance $\mathrm{C}_{\mathrm{t}}$ (cca. $4.5 \mathrm{pF}$ ). The output impedance of the transimpedance terminal of this current source is high.

The output circuits of comparators are in the nature of pulse circuits and thus a maximum rate of change in the output voltage is usually required in comparison. This parameter has a direct influence on the switching time. In the classical comparator with operational amplifier the switching time is given by the slew rate of the operational amplifier used. In comparators with current conveyors the switching time should be substantially shorter.

\section{HYSTERESIS COMPARATOR WITH CCII+}

Similarly as in [12], transimpedance amplifiers AD844 [16] including CCII+ were used to implement the comparator. The schematic diagram of a hysteresis comparator implemented using two CCII+ conveyors is shown in Fig. 3 .

From the connection of non-inverting hysteresis comparator with operational amplifier the equivalent connection of noninverting or inverting hysteresis comparator with CCII+ can be derived. The connection given in Fig. 3 combines two possibilities. The circuit part containing the $\mathrm{CCII}+{ }_{\mathrm{A}}$ current conveyor represents the non-inverting hysteresis comparator while the part containing the $\mathrm{CCII}+{ }_{\mathrm{B}}$ current conveyor performs the function of an inverting hysteresis comparator. Then output voltage $V_{\text {OUT1 }}$ is the output of the non-inverting

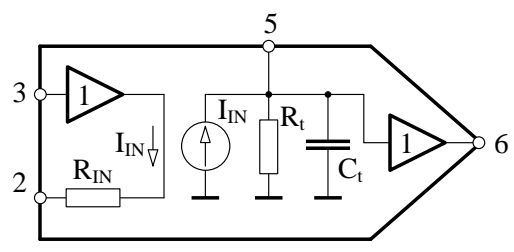

(a)

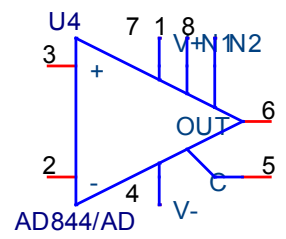

(b)

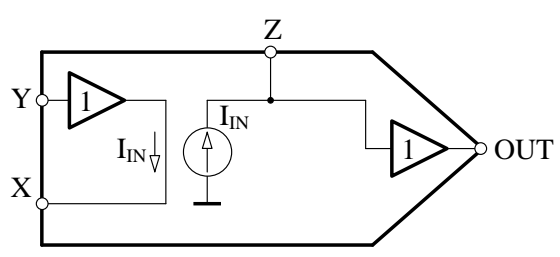

(c)

Fig. 2. (a) Internal connection of circuit AD844 [16], (b) symbol of circuit AD844 in PSpice program, (c) idealized model of circuit AD844

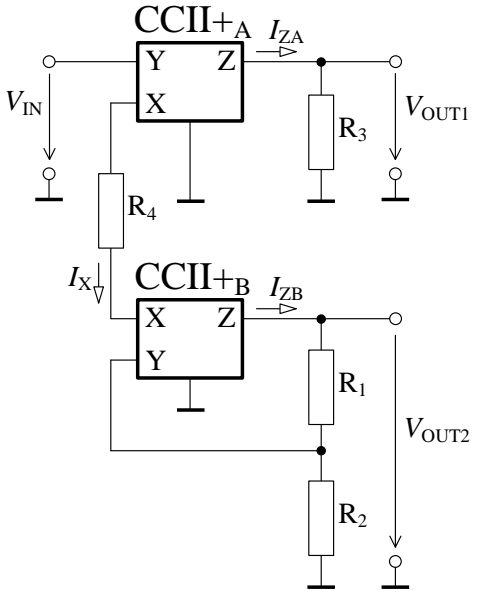

Fig. 3. Non-inverting and inverting hysteresis comparator with two CCII+s

hysteresis comparator, and output voltage $V_{\mathrm{OUT} 2}$ is the output of inverting hysteresis comparator.

To describe the activity and determine the values of positive comparison voltage $+V_{\mathrm{P}}$ and negative comparison voltage $-V_{\mathrm{N}}$ of the comparator from Fig. 3 we will start from the knowledge of CCII+ in the AD844 circuit as given above. In this case the most important parameter of CCII+ is the magnitude of the transimpedance formed by a parallel connection of resistance $R_{t}$ and capacitance $C_{t}$. These elements form the impedance of output terminal $\mathrm{Z}$. The output resistance $\mathrm{R}_{\mathrm{X}}$ of low-impedance terminal $\mathrm{X}$ also needs to be taken into consideration.

Consider that the output voltage $V_{\text {OUT1 }}$ can acquire values $+V_{\text {OUT_SAT }}$ or $-V_{\text {OUT_SAT }}$, with the output voltage $V_{\text {OUT2 }}$ always acquiring the opposite values, i.e. $-V_{\text {OUT_SAT }}$ and $+V_{\text {OUT_SAT. }}$ The outputs $V_{\text {OUT1 }}$ and $V_{\text {OUT2 }}$ are mutually complementary.

Consider that the output voltage $V_{\mathrm{OUT} 2}$ of conveyor $\mathrm{CCII}+{ }_{\mathrm{B}}$ has a maximum positive level, i.e. $V_{\mathrm{OUT} 2}=+V_{\mathrm{OUT}} \mathrm{SAT}$, in which case the voltage $+V_{\mathrm{P}}$ on port $\mathrm{Y}$ of current conveyor $\mathrm{CCII}_{\mathrm{B}}$ is given by the relation:

$$
+V_{\mathrm{P}}=+V_{\text {OUT_SAT }} \frac{R_{2}}{R_{1}+R_{2}}=+V_{\text {OUT_SAT }} \beta .
$$

If on the contrary there is on the output of conveyor $\mathrm{CCII}+\mathrm{B}$ a minimum negative level, $V_{\text {OUT2 }}=-V_{\text {OUT_SAT }}$, then the voltage on port $\mathrm{Y}$ of this conveyor is:

$$
-V_{\mathrm{N}}=-V_{\mathrm{OUT} \_\mathrm{SAT}} \frac{R_{2}}{R_{1}+R_{2}}=-V_{\mathrm{OUT} \_\mathrm{SAT}} \beta .
$$

By the definition of current conveyor CCII+ it holds that $V_{\mathrm{X}}=V_{\mathrm{Y}}$, so that the voltage on port $\mathrm{Y}$ will be repeated also on port $\mathrm{X}$ of $\mathrm{CCII}+{ }_{\mathrm{B}}$. Therefore, the current flowing into terminal $\mathrm{X}$ can be expressed as:

$$
I_{\mathrm{X}}=\frac{V_{\mathrm{IN}}-V_{\mathrm{OUT}_{\mathrm{S}} \mathrm{AT}} \beta}{2 R_{\mathrm{X}}+R_{4}} .
$$

From the conveyor definition it further follows that the output current of conveyor $\mathrm{CCII}_{\mathrm{A}}$ is $I_{\mathrm{ZA}}=I_{\mathrm{X}}$, and the output current of conveyor $\mathrm{CCII}+{ }_{\mathrm{B}}$ is $I_{\mathrm{ZB}}=-I_{\mathrm{X}}$. The output voltage 
of conveyor $\mathrm{CCII}+{ }_{\mathrm{A}}$ is then given by the relation:

$$
V_{\mathrm{ZA}}=V_{\mathrm{OUT} 1}=\frac{V_{\mathrm{IN}}-V_{\mathrm{OUT} \_\mathrm{SAT}} \beta}{2 R_{\mathrm{X}}+R_{4}} \frac{R_{\mathrm{t}}}{1+s R_{\mathrm{t}} C_{\mathrm{t}}}
$$

and the output voltage of conveyor $\mathrm{CCII}+{ }_{\mathrm{B}}$ is:

$$
V_{\mathrm{ZB}}=V_{\mathrm{OUT} 2}=-\frac{V_{\mathrm{IN}}-V_{\mathrm{OUT} \_\mathrm{SAT}} \beta}{2 R_{\mathrm{X}}+R_{4}} \frac{R_{\mathrm{t}}}{1+s R_{\mathrm{t}} C_{\mathrm{t}}},
$$

where $s=\mathrm{j} \omega$, whereas $\omega$ is the angular frequency. Simplified relations can be obtained in the form of

$$
\begin{gathered}
V_{\mathrm{ZA}}=V_{\mathrm{OUT} 1}=\frac{R_{\mathrm{t}}}{2 R_{\mathrm{X}}+R_{4}}\left(V_{\mathrm{IN}} \mp V_{\mathrm{OUT}_{\mathrm{S}} \mathrm{SAT}} \beta\right), \\
V_{\mathrm{ZB}}=V_{\mathrm{OUT} 2}=-\frac{R_{\mathrm{t}}}{2 R_{\mathrm{X}}+R_{4}}\left(V_{\mathrm{IN}} \mp V_{\mathrm{OUT}_{\mathrm{OSAT}}} \beta\right),
\end{gathered}
$$

where the negative sign "-"and positive sign "+"within the parentheses denote the state of comparator output voltages $V_{\text {OUT1 }}$ and $V_{\text {OUT2 } 2}$ If $V_{\text {OUT1 }}=-V_{\text {OUT_SAT }}$, then $V_{\text {OUT2 }}=$ $+V_{\text {OUT_SAT }}$, and if $V_{\text {OUT1 }}=+V_{\text {OUT_SAT }}$ then $V_{\text {OUT2 }}=$ $-V_{\text {OUT_SAT. }}$

After switching the conveyor outputs to the values $V_{\text {OUT1 }}=$ $-V_{\text {OUT_SAT }}$ and $V_{\text {OUT2 }}=+V_{\text {OUT_SAT }}$ the input voltage $V_{\text {IN }}$ must drop below the value $-V_{\mathrm{OUT}} \mathrm{SAT} \beta$. The comparator hysteresis is defined as the difference between the positive and the negative comparison level of input voltage and is thus given by the relation:

$$
\begin{aligned}
h & =+V_{\mathrm{P}}-\left(-V_{\mathrm{N}}\right)=+V_{\mathrm{OUT} \_\mathrm{SAT}} \beta-\left(-V_{\mathrm{OUT} \_\mathrm{SAT}} \beta\right)= \\
& =2 \beta V_{\text {OUT_SAT }} .
\end{aligned}
$$

\section{Computer Simulation of Hysteresis COMPARATOR WITH CCII+}

The operation of the comparator from Fig. 3 was tested in computer simulation. In the MicroCap simulation program the model of the AD844AD circuit will be used. The circuit parameters set for the simulation were: supply voltage $V_{\mathrm{CC}}=$ $\pm 15 \mathrm{~V}$, saturation voltage $V_{\text {OUT_SAT }}=10 \mathrm{~V}$, the resistance values chosen are $R_{1}=R_{2}=10 \mathrm{k} \Omega$, consequently $\beta=$ $0.5, R_{3}=20 \mathrm{k} \Omega$, and $R_{4}=1 \mathrm{k} \Omega$. The calculated value of comparison voltage is $+V_{\mathrm{P}}=5 \mathrm{~V}$ and the comparator hysteresis is then $h=10$. For the chosen $V_{\mathrm{IN}}=10 \mathrm{~V}$ the output current magnitudes of the two current conveyors are $I_{\mathrm{ZA}}=4.5 \mathrm{~mA}$ and $I_{\mathrm{ZB}}=-4.5 \mathrm{~mA}$.

Simulation results are given for non-inverting comparator in Fig. 4(a), and for inverting comparator in Fig. 4(b), Arrowheads in the waveforms follow the direction of the change in input voltage $V_{\mathrm{IN}}$. As can be seen, the circuit performs the expected function. The circuit part containing the $\mathrm{CCII}+{ }_{\mathrm{B}}$ fulfills the function of inverting hysteresis comparator, the part with $\mathrm{CCII}+{ }_{\mathrm{A}}$ performs the function of non-inverting hysteresis comparator.

\section{Digital Control of Hysteresis And EXPERIMENTAL MEASUREMENTS}

For the digital control of hysteresis magnitude the comparator connection including a CCII+ was proposed as given in Fig. 5. The initial basic connection given in Fig. 3 was complemented with a multiplier with digital-to-analog converter AD7533 [21], operational amplifier LM741 (which is connected as a voltage follower), and a third CCII+ current conveyor AD844. Voltage from the divider $R_{1}-R_{2}$ is conveyed to the multiplier, where it is multiplied by the value of a 10-bit input word $D$, which sets the hysteresis magnitude. Therefore, it is necessary to multiply the relations (2), (3) and (9) by the value $D$. The value $D$ expresses the binary fraction value of 10-bit digital input word DAC; examples of calculating $D$ for some of the combinations are given in Table If. In the comparator connection implemented, hysteresis can be set in an interval $h=0 \mathrm{~V}$ to $h=12.125 \mathrm{~V}$, in dependence on the set combination of 10-bit digital word $D$.

The measured waveforms for the control word $D=$ 1111111111 is given in Fig. 6. For this value of the number $D$ the maximum value of comparator hysteresis is obtained, $h=12.125 \mathrm{~V}$. For $D=1000000000$ the waveform is shown in Fig. 7 while for $D=0000000001$ it is shown in

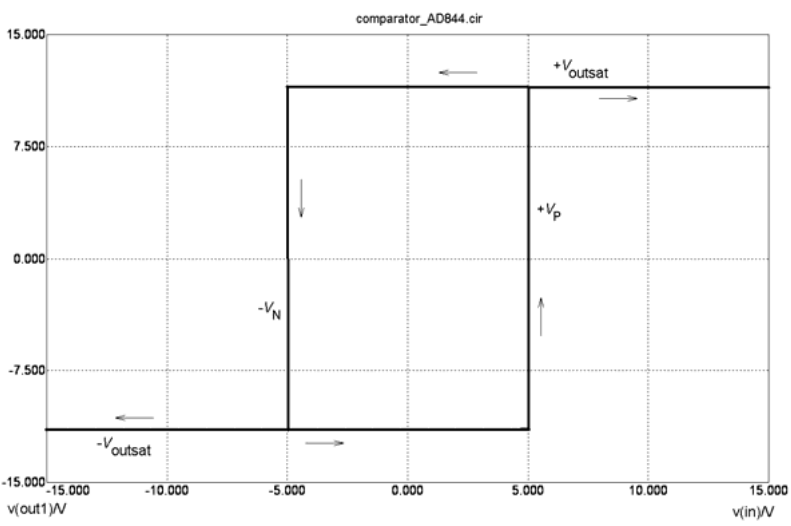

(a)

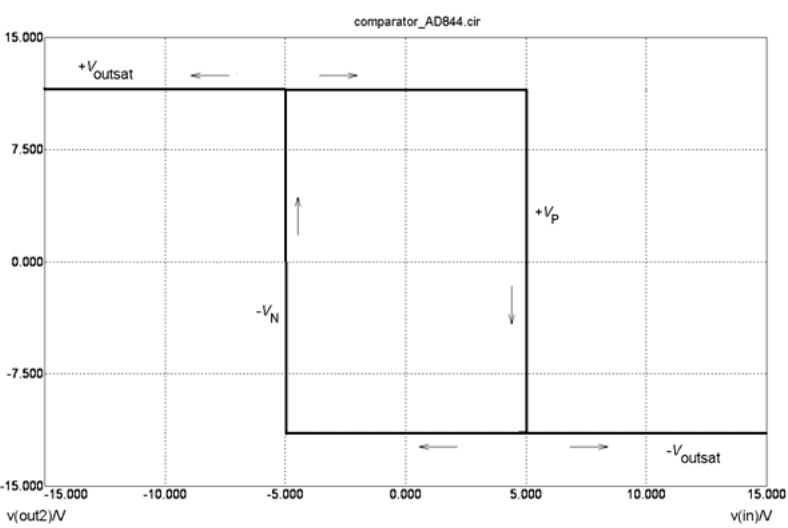

(b)

Fig. 4. (a) non-inverting, (b) inverting waveform of hysteresis characteristic of comparator from Fig. 3 
TABLE I

BINARY FRACTION REPRESENTATION OF SOME COMBINATIONS OF 10-BIT DAC INPUT DIGITAL INPUT BINARY FRACTION VALUE

\begin{tabular}{cc}
\hline Digital input $(\mathrm{MSB} \rightarrow$ LSB) & Binary fraction value \\
\hline \hline 1111111111 & $1023 / 1024$ \\
1000000001 & $513 / 1024$ \\
1000000000 & $512 / 1024$ \\
0111111111 & $511 / 1024$ \\
0000000001 & $1 / 1024$ \\
0000000000 & $0 / 1024$ \\
\hline
\end{tabular}

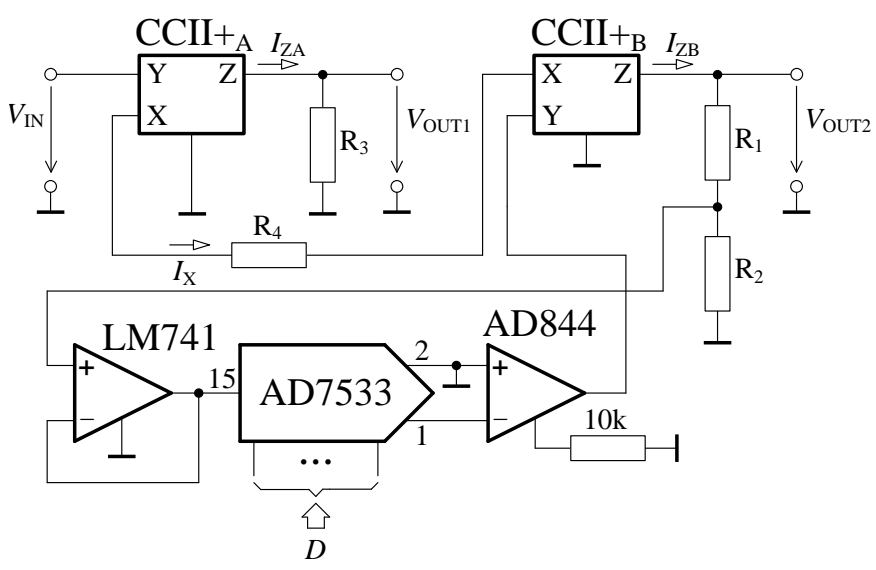

Fig. 5. Design schematic of comparators with variable hysteresis

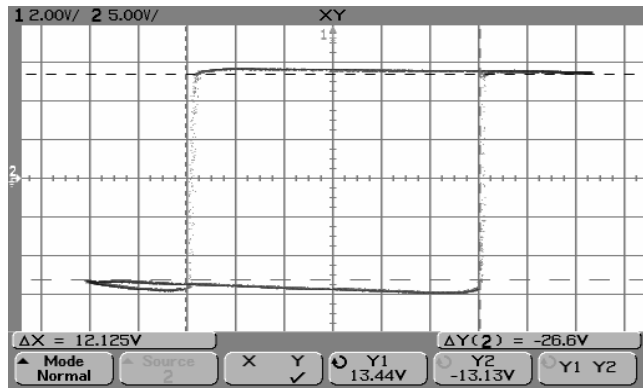

(a)

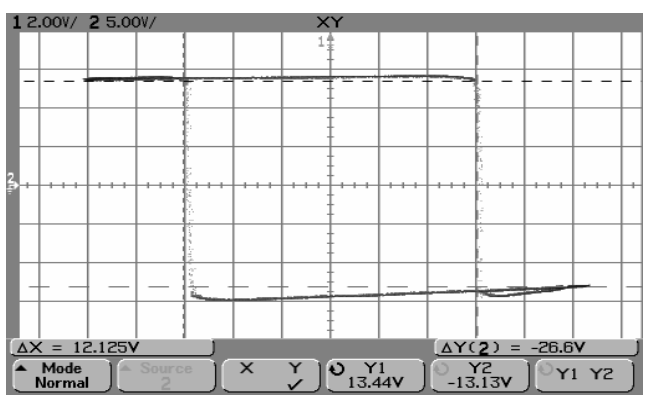

(b)

Fig. 6. Hysteresis loop for $D=1111111111$, (a) non-inverting comparator (b) inverting comparator

Fig. 8. The value of hysteresis $h$ in the comparator is given by the parameter of $\Delta \mathrm{X}$ cursors in the left bottom corner while the parameter $\Delta \mathrm{Y}$ in the right bottom corner gives the value of $2 V_{\text {OUT_SAT }}$. The testing input signal was a sinusoidal waveform of frequency $2.2 \mathrm{kHz}$.

With increasing frequency of the input signal the magnitude of the hysteresis value changes. The waveforms of

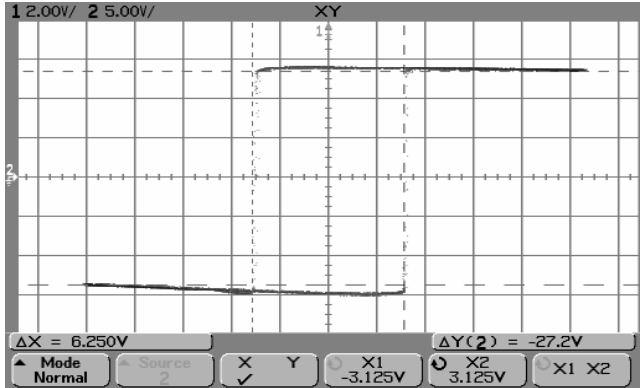

(a)

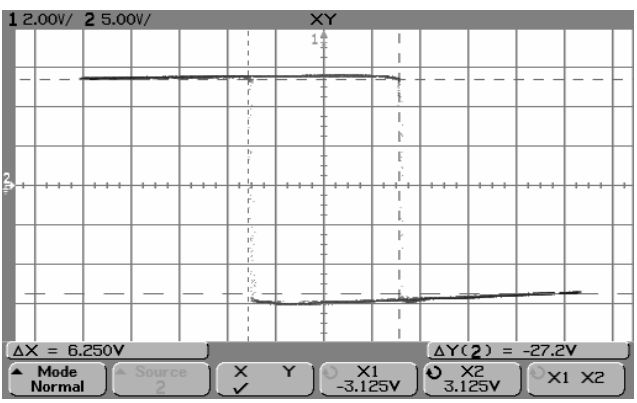

(b)

Fig. 7. Hysteresis loop for $D=1000000000$, (a) non-inverting comparator (b) inverting comparator

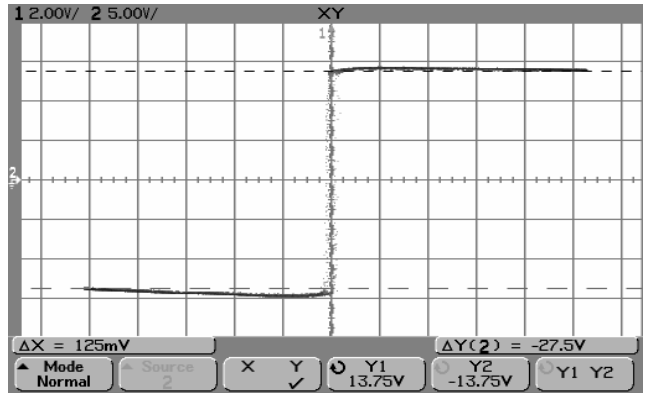

(a)

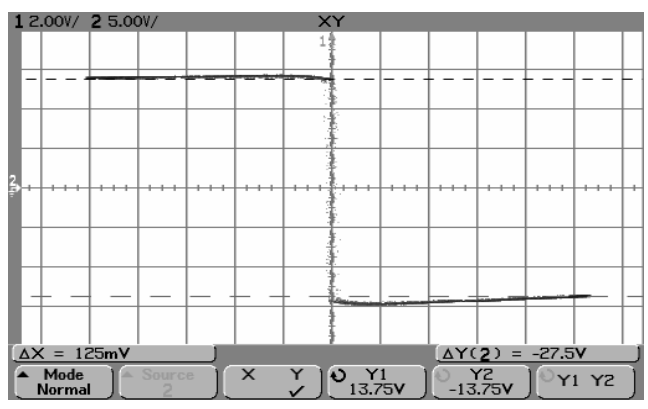

(b)

Fig. 8. Hysteresis loop for $D=0000000001$, (a) non-inverting comparator (b) inverting comparator

output signal of inverting comparator at input signal frequency $5.5 \mathrm{kHz}$ and $D$ set to 0000000001 is given in Fig. 9(a) while Fig. 9(b) gives the waveform for input frequency $650 \mathrm{kHz}$. The two waveforms can be compared with the oscillograms given in Fig. 8(b), For the above value of input word $D$ the hysteresis should be $h=125 \mathrm{mV}$ but the actual hysteresis value is $300 \mathrm{mV}$. If the input signal frequency increases, the 


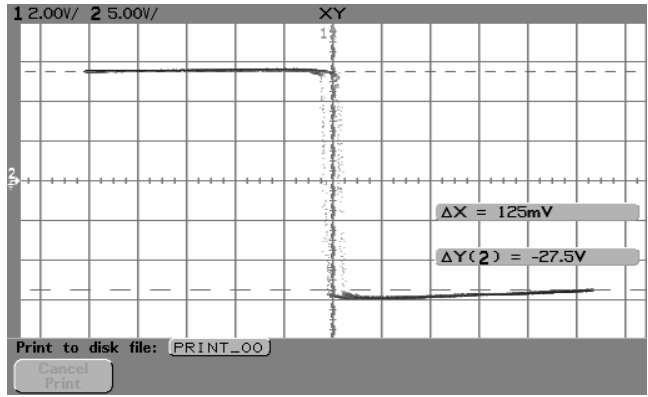

(a)

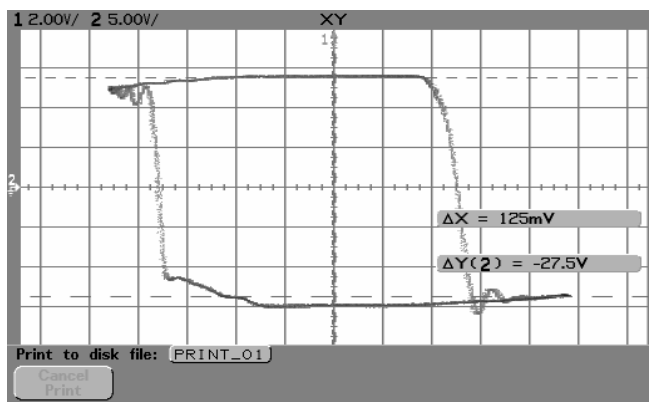

(b)

Fig. 9. Hysteresis loop of inverting comparator for $D=0000000001$, (a) frequency $f=5.5 \mathrm{kHz}$ (b) frequency $f=650 \mathrm{kHz}$

hysteresis loop gets more extended and the dynamic properties of current conveyors come to be fully shown. At the time of switching, noticeable overshooting can be observed on the waveforms. This has a considerable effect on comparator precision, showing in the utilizable frequency band of comparator with AD844.

\section{CONCLUSION}

The paper presents the solution of a voltage comparator with current conveyors CCII+. A theoretical analysis and computer simulation were performed and a digitally controlled inverting and non-inverting comparator has been proposed. The comparator has some pulse circuit elements and therefore a maximum rate of output voltage change is usually required. Measuring on an experimental specimen shows the results obtained. The values of hysteresis $h$ measured for three chosen combinations of $D$, i.e. full extent of $h$, half the extent of $h$, and the least value of $h$, were compared with calculated values. The deviation from these values was cca. $3 \%$ for individual values of $D$. In the connection given, there is evidently a drop in voltage, obviously due to the AD7533 multiplier. Measuring the comparator without multiplier did not exhibit this error. Thus the good functionality of the comparator was verified and the advantage of the current mode was shown. Further work will focus on obtaining a higher operating frequency.

\section{REFERENCES}

[1] K. C. Smith and A. Smith, "The Current Conveyor: a New Circuit Building Block,"IEEE Proc., Vol. 56, pp. 1368-1369, 1968.

[2] A. Sedra and K. C. Smith, "A second-generation current conveyor and its application,"IEEE Trans. Circuit Theory, Vol. 17, pp. 132-134, 1970.

[3] A. Fabre, "Third-generation current conveyor: a new helpful active element,"Electronics Letters, Vol. 31, No. 5, pp. 338-339, 1995.
[4] M. Sagbas, K. Fidanboylu, and M. C. Bayram, "Triple-input Singleoutput Voltage-mode Multifunction Filter Using Only Two Current Conveyors", Trans. Engineering, Computing and Technology, Vol. 4, pp. 105-108, 2005

[5] S. Minaei, O. K. Sayin, and H. Kuntman, "A new CMOS electronically tunable current conveyor and its application to current-mode filters", Tran. Circuits and Systems I, Vol. 53, pp. 1448-1457, 2006.

[6] S. A. Mahmoud, M. A. Hashiesh, and A. M. Soliman, "Digitally controlled fully differential current conveyor: CMOS realization and applications", in Proc. IEEE Int. Symp. Circuits and Systems - ISCAS, Vol. 2, pp. 1622-1625, 2005.

[7] P. Prommee, M. Somdunyakanok, and S. Toomsawasdi, "CMOS-based current-controlled DDCC and its applications", in Proc. IEEE Int. Symp. Circuits and Systems - ISCAS, pp. 1045-1048, 2010.

[8] S. Ozoguz and A. Acar, "On the realization of floating immittance function simulators using current conveyors", Int. J. Electronics, Vol. 85, No. 4, pp. 463-475, 1998.

[9] U. Cam, O. Cicekoglu, and H. Kuntman, "Universal series and parallel immittance simulators using four terminals floating nullors,'Analog Integrated Circuit and Signal Processing, Vol. 25, No. 1, pp. 5966, 2000.

[10] E. Arslan, B. Metin, C. Cakir, O. Cicekoglu, "A novel grounded lossless inductance simulator with CCI", in Proc. Int. XII. Turkish Symposium on Artificial Inteligence and Neural Networks, 2003.

[11] E. Yuce, S. Minaei, and O. Cicekoglu, "A novel grounded inductor realization using a minimum number of active and passive components", ETRI Journal, Vol. 27, pp. 427 - 432, 2005.

[12] S. Bima, A. Khan, S. Roy, and K. Dey, "Programmable Hysteresis Comparator Circuits using Current Conveyor,"J. Instrum. Soc. India, No. 32, pp.85-93, 1997.

[13] S. Del Re, A. De Marcellis, G. Ferri, and V. Stornelli, "Low voltage integrated astable multivibrator based on a single CCII", in Proc. Research in Mincroelectronics and Electronics Conference, pp. 177-180, 2007.

[14] P. Silapan and M. Siripruchyanun, "A Simple Current-mode Schmitt Trigger Employing Only Single MO-CTTA", in Proc. 6th Int. Conf. Electrical Engineering/Electronics, Computer, Telecommunications and Information Technology - ECTI-CON, Vol. 01, pp. 556-559, 2009.

[15] P. Silapan and M. Siripruchyanun, "Fully and electronically controllable current-mode Schmitt triggers employing only single MOCCCDTA and their applications ", Analog Integr Circ Sig Process, doi: 10.1007/s10470-010-9593-2, Vol. 68, pp. 111-128, 2011.

[16] Datasheet AD844: $60 \mathrm{MHz} 2000 \mathrm{~V} / \mu$ s Monolithic Op Amp, Analog Devices, Rev. F. 2009

[17] A. Fabre, O. Saaid, F. Wiest, and C. Baucheron, High frequency applications based on a new current controlled conveyor, IEEE Trans. Circuits Syst.-I, Vol. 43, No. 2, pp. 82-90, 1996.

[18] H.O. Elwan and A.M. Soliman, Novel CMOS differential voltage current conveyor and its applications, IEE Proc. Circuits, Devices, Systems, Vol. 144, No. 3, pp. 195-200, 1997

[19] S. Minaei, O.K. Sayin, and H. Kuntman, A new CMOS electronically tunable current conveyor and its application to current-mode filters, IEEE Trans. Circuits Systems I, Vol. 53, No. 7, p. 1448-1457, 2006.

[20] W. Surakampontorn and K. Kumwachara, CMOS-based electronically tunable current conveyor, Electronics Letters, Vol. 28, No. 14, pp. 13161317, 1992.

[21] Datasheet AD7533: CMOS low cost 10-bit multiplying DAC, Analog Devices, Rec. C, 2007.

Jiri Misurec MSc. (1985), Ph.D. (1991), Ass. Prof. (2007) is with the Brno University of Technology, Dept. of Teleinformatics, Czech Republic. He gives lectures in and leads the exercise for the subject "Analog technique"and gives lectures in the course "Digital Signal Processing". His research interest is focused on the area of analog technique, converters, especially on converters working both in voltage and current mode. Now he is interested in generalization of sensitivity analysis of transfer functions. This should be used for comparison of newly developed applications. In the latest he also cooperates with a number of companies on implementation of fundamental research results into practice.

Jaroslav Koton received the M.Sc. an Ph.D. degree in electrical engineering from the Brno University of Technology, Czech Republic, in 2006 and 2009, respectively. He is currently an Assistant Professor at the Department of Telecommunications of the Faculty of Electrical Engineering and Communication of Brno University of Technology, Czech Republic. His current research is focused on linear and non-linear circuit designing methods with current or voltage conveyors, and current active elements. He is an author or co-author of about 85 research articles published in international journals or conference proceedings. Dr. Koton is a Member of IEEE and IACSIT. 